\title{
Influence of Temperature and Moisture on Aging Degree of Transformer Oil Paper Insulation
}

\author{
Tianchu Gao* \\ North China Electric Power University School of Electrical and Electronics Engineering, China Beijing, \\ 102206 \\ *Corresponding Author email: 1103206267@qq.com
}

Keywords: Temperature, Moisture, Transformer Oil Paper Insulation

\begin{abstract}
The higher the temperature, the faster the aging of oil paper insulation, and the faster the polymerization degree drops. The relationship between aging rate change and temperature stress change is not linear. The more moisture content of oil paper insulation, the faster the aging of oil paper insulation, and the faster the polymerization degree drops. The influence of temperature factor on the aging rate of oil paper insulation will increase with the increase of moisture content in the oil paper insulation system. The influence of water factors on the aging rate of oil paper insulation increased with the increase of temperature. That is, temperature and moisture have a synergistic effect on the aging of oil paper insulation. The higher the aging temperature, the higher the moisture content of oil paper insulation, and the faster the furfural generation rate. The furfural content in oil increased slowly at the beginning and increased rapidly in the later stage. The distribution of furfural in oil paper will be affected by moisture content, and the increase rate of furfural content in oil is not corresponding to the rate of decrease in polymerization degree.
\end{abstract}

\section{Introduction}

\subsection{The significance of studying the aging of transformer oil paper insulation}

The great demand for energy in modern society has promoted the rapid development of the power industry [1]. In the context of the continuous improvement of the national economy, the interconnection of regional power grids and the high voltage long distance transmission have been realized [2]. Once the power system fails, it will cause huge economic losses, and it may also lead to serious public safety and serious social impact [3-5].

The transformer is one of the most important and expensive equipment in the power system [6]. According to statistics, the fault caused by the transformer insulation problem accounts for about $80 \%$ of the total fault, and the fault caused by the insulation aging accounts for a large proportion [7]. Therefore, the correct and effective evaluation of the oil paper insulation status inside the transformer is of great significance for the safe and stable operation of the power grid [8-10].

\subsection{Aging form and influencing factors of transformer oil paper insulation}

The oil paper insulation system consisting of ordinary cowhide insulating paper and 25\# mineral oil is the main form of internal insulation of power transformers. In the long run, the following four forms of aging will occur.

\subsubsection{Thermal aging}

Thermal aging is the main form of insulation deterioration in the transformer. The gas and organic acid produced after aging will cause the heat dissipation of the transformer to deteriorate, the temperature is further rising, and the aging process is heated to form a vicious cycle. At the same time, bubbles may cause partial discharge in strong electric field, resulting in electrical aging.

The life of insulation determined by thermal aging is inversely proportional to the rate of chemical 
reaction. It is generally believed that the life of insulation will be reduced by half if the temperature rises by $10^{\circ} \mathrm{C}$.

\subsubsection{Electrical aging}

Electrical aging refers to the aging of insulation in the long term of electric field. A series of physical and chemical effects under the action of the electric field, the charged particle produced by the discharge process and the thermal effect of the dielectric will break the insulating material and lead to the decrease of the insulation performance. However, field strength is not the main cause of electrical aging.

The transformer insulation will produce small bubbles in the process of chemical reaction, drying, transportation and so on. The breakdown field of these bubbles is low, and it is easy to occur partial discharge at the concentration of electric field. The discharge process will decompose the transformer oil and produce various hydrocarbon gases, and further accelerate the process of electrical aging. Partial discharge is the main cause of electrical aging.

\subsubsection{Mechanical aging}

The transformer windings will be subjected to mechanical stress during the operation process. Under the action of mechanical stress, the micro defects in the insulation have regular movement, forming cracks and gradually expanding, resulting in mechanical aging.

The size of mechanical load will affect the aging rate, and strong electric field and high temperature will also accelerate the aging process.

\subsubsection{Environmental aging}

The factors causing environmental aging include water, pollution, oxygen and so on. The main consequence is the damp of the insulation system, and the insulation resistance and dielectric loss increase after damp, which may cause thermal breakdown.

\subsection{Aging mechanism of transformer oil paper insulation}

\subsubsection{The aging mechanism of oil}

The aromatic hydrocarbons in the oil will take the lead in the degradation of the transformer under the action of thermal stress and oxygen during the operation of the transformer, and produce the fault gases such as $\mathrm{CO}$ and $\mathrm{CO} 2$, along with the phenomena of partial discharge and arc discharge. As the aging degree of insulating oil increases, its viscosity increases, dielectric loss increases and breakdown voltage decreases. The aging of oil can be improved by replacing new oil. 


\subsubsection{The aging mechanism of paper}

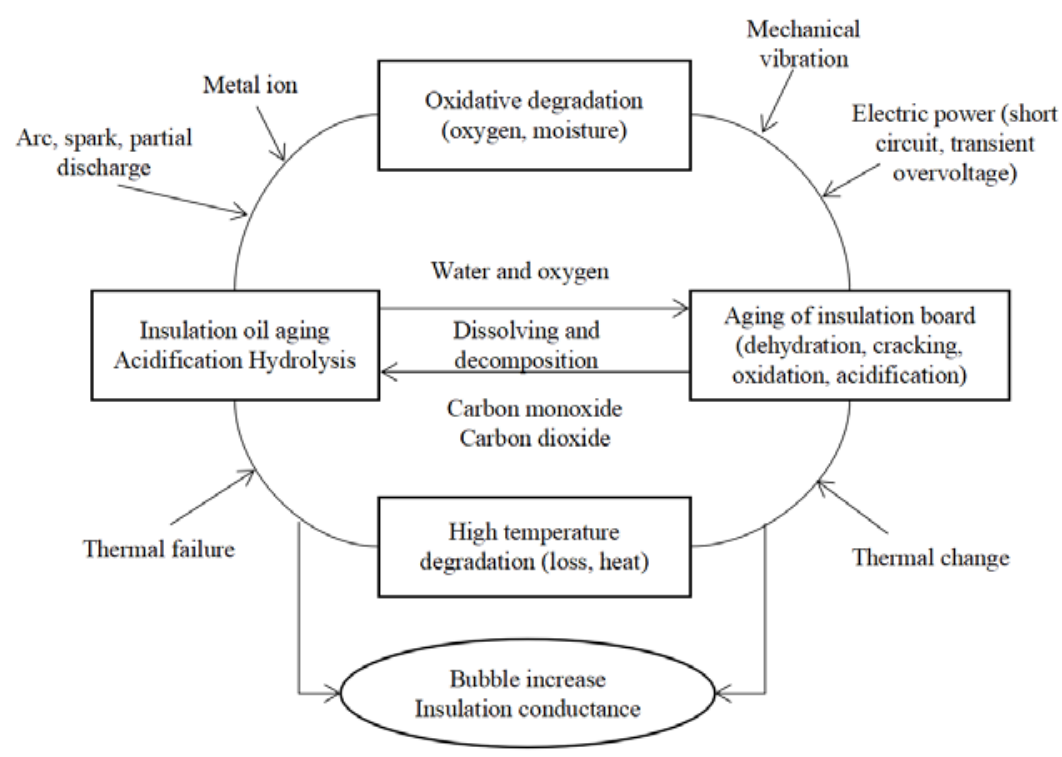

Fig.1

The degradation of cellulose in paper causes aging. Degradation includes three forms: pyrolysis, oxidative degradation and hydrolysis, in which hydrolysis is the main factor, and the hydrogen ions that are ionized by organic acids can catalyze the hydrolysis reaction under acidic conditions. (As shown in the figure 1).

\subsection{Aging characteristics of transformer oil paper insulation}

Chemical characteristic parameter method: the degree of polymerization of insulating paper DP; furfural content in oil; total amount of $\mathrm{CO}$ and $\mathrm{CO} 2$ and ratio.

Electrical characteristic parameter method: partial discharge measurement; dielectric response measurement

\section{Brief Introduction of Experiment}

From the above, it is important to study the aging of transformer oil paper insulation for users, power systems and even the development of national economy. In order to study the influence of temperature and moisture, we can choose some kind of oil paper combination, design contrast test based on the control variable method, record the changing trend of the aging characteristic quantity, and draw a conclusion. At the same time, the variety of oil and paper and the variety of applied voltage may lead to the different influence of temperature and moisture on its aging degree, and summarize the experimental content and process briefly.

\subsection{Experimental design}

Experiment 1: Most of the experiments were made of insulating cardboard and 25\# mineral oil as samples, controlling the initial water content of the sample, aging at different ambient temperatures, or controlling the aging experiments of samples with different initial water content at the same temperature.

Experiment 2: The change rules of oil and paper are analyzed, /25\# mineral oil of plant insulation oil is selected, and ordinary cowhide transformer insulation paper / thermal stable insulating paper is used as the experimental material.

Experiment 3: The influence of DC, AC and AC superimposed DC electric field on the insulation of water is analyzed. 


\subsection{Selection of experimental temperature}

The average temperature of the oil immersed transformer is 65-85 degrees, and the local maximum temperature is about 95 degrees Celsius. According to experiment one or two, if the aging temperature is too low, which is not conducive to the research, the actual temperature of $90 \mathrm{C}$ is chosen as the lowest test temperature. The flash point of 25\# transformer oil is about $140 \mathrm{C}$. When the transformer oil is heated to the flash point, it may cause an explosion. When the temperature is higher than 150, the degradation mechanism of the cellulose insulating paper may change, so the maximum temperature is selected at 130. In order to draw a certain gradient of temperature conditions, the average temperature of the highest and minimum temperature is chosen as 110 experimental temperatures as the third experimental temperature. For experiment three, the 60-degree $\mathrm{C}$ approaching the normal working temperature of transformer is chosen as the research objective.

\subsection{Selection of experimental water content}

According to the voltage grade of the transformer, the water content in the oil is $10 \mathrm{~L} / \mathrm{L}-20 \mathrm{mu} \mathrm{L} / \mathrm{L}$, and the residual moisture in the paper is generally $0.2 \%-0.5 \%$, but in fact, during the installation or maintenance of the transformer, many cases will cause the insulation paper to absorb water. In the study of insulation paper aging test at home and abroad, the initial content of moisture content varies from $<0.5 \%$ to $9 \%$. Therefore, the initial water content of insulation paper is $1 \%, 3 \%, 5 \%$, considering the actual situation and the consideration of setting water content gradient.

\subsection{Characteristic parameters and measurement methods}

The degree of polymerization of insulating paper: Viscosity method

The content of furfural in oil: High speed liquid chromatograph

Oleic acid value: Determination of acid value of transformer oil and turbine oil in operation (BTB method)

Water in paper: Combination of DL32 and DO308 drying furnace

Water in oil: DL32 Carlo tramp Titrant

\subsection{Experimental process}

Experiment 1: The insulation paper samples with initial moisture content of $1 \%, 3 \%$ and $5 \%$ were prepared for aging tests in the environment of $90 \mathrm{C}, 110 \mathrm{C}$ and $130 \mathrm{C}$ respectively. The changes of the degree of polymerization of insulating paper, water content in paper, dielectric properties of insulating paper, water content in oil, content of furfural in oil, oil acid value and so on were measured during the aging process.

Experiment 2: Preparation of 4 medium oil paper insulation composite samples: 25\# mineral oil + ordinary cowhide insulating paper (O1P1), 25\# mineral oil + heat stabilized paper (O1P2), vegetable oil + ordinary kraft paper (O2P1), vegetable oil + heat stabilized paper (O2P2). Experiments were carried out in an aging box at 90-degree $\mathrm{C}, 110$-degree $\mathrm{C}$ and 130-degree $\mathrm{C}$ to measure paper polymerization degree, oleic acid value and moisture content in oil.

Experiment 3: The breakdown voltage of mineral oil kraft paper insulation under alternating current and DC voltage is tested by continuous boosting method. 


\section{Effect of Temperature and Moisture on Aging Degree and Characteristic Product Formation of Oil Paper Insulation}

\subsection{Experiment 1}

\begin{tabular}{|c|c|}
\hline Factor & Temperature influence \\
\hline Paper polymerization degree & $\begin{array}{l}\text { The higher the temperature, the } \\
\text { faster the aging, and the faster the } \\
\text { polymerization degree decreases. } \\
\text { The degree of polymerization } \\
\text { decreases rapidly with aging time } \\
\text { and tends to saturation when it } \\
\text { reaches a certain degree. The } \\
\text { effect of temperature factor on the } \\
\text { aging rate increases with the } \\
\text { increase of moisture content. }\end{array}$ \\
\hline
\end{tabular}

Furfural in oil

The higher the temperature, the faster the furfural formation rate is, the higher the furfural content in the oil is.

Furfural increased slowly at first and then increased dramatically after a period of time. The content of furfural decreased rapidly at 90 degree $C$ and 110 degree $C$ at 5\% degrees of aging, probably due to decomposition at high temperature.

Water influence

The higher the initial water content, the faster the aging, and the faster the DP drops. The influence of water factors on the aging rate of oil paper insulation will increase with the increase of temperature.

The effect of temperature and moisture on aging has a synergistic effect.

The higher the initial water content, the faster the furfural production rate; the higher the furfural content in the oil. The change of furfural content is not exactly the same as that of DP. In the actual operation, the influence of water and other factors on the distribution ratio of furfural in oil paper should be considered when judging the aging state according to the furfural content in the oil.

Oleic acid value The overall variation of oleic acid value and furfural content is the same, which corresponds to the law of the degree of polymerization decline. When the initial water content is the same, the higher the temperature is, the faster the DP drops and the higher the oleic acid content. Under certain conditions, DP decreased rapidly, but oleic acid increased slowly, resulting in inconsistency.

At the same temperature, the higher the water content is, the faster the DP drops and the higher the oleic acid content.

The change of oleic acid value has no obvious DP.

The rate of oleic acid formation of different samples at the same temperature has little difference. The oleic acid value increased slowly with aging, and then increased significantly after reaching a certain degree.

Water in paper The water content fluctuates and the trend is basically the same. When the temperature increases, the time of the extreme point of the fluctuation curve is shorter. The temperature has no influence on the fluctuation trend of water content. The water content of the sample with low temperature is higher than that of the temperature.

Water in oil The shorter the time of the extreme value of the fluctuation curve is the same as the moisture content in the paper.

The fluctuation trend is determined by the initial water content. $1 \%$ of the samples first increased and then decreased, 3\% and $5 \%$ decreased first and then increased, then slowly fluctuated. The greater the initial moisture content, the greater the moisture content in paper.

First increase, then increase or decrease alternant fluctuation. The greater the initial water content, the greater the fluctuation 


\subsection{Experiment 2}

\begin{tabular}{|c|c|c|c|c|}
\hline & O1P1 & O1P2 & O2P1 & O2P2 \\
\hline Water in oil & $\begin{array}{l}\text { The content has } \\
\text { been low. } \\
\text { Fluctuation } \\
\text { trend. } \\
\text { Fluctuation } \\
\text { trend. } \\
\text { Undulation }\end{array}$ & $\begin{array}{l}\text { The content has } \\
\text { been low. } \\
\text { Fluctuation } \\
\text { trend. } \\
\text { Fluctuation } \\
\text { trend. Small } \\
\text { fluctuation }\end{array}$ & $\begin{array}{l}\text { First, it rises to } \\
\text { max, and then } \\
\text { descends later. } \\
\text { The higher the } \\
\text { temperature, the } \\
\text { shorter the max, } \\
\text { the shorter the } \\
\text { time. }\end{array}$ & $\begin{array}{l}\text { Down to } \\
\text { smooth, slightly } \\
\text { rising in the later } \\
\text { period. The } \\
\text { higher the } \\
\text { temperature, the } \\
\text { shorter the time } \\
\text { to reach the } \\
\text { smooth. }\end{array}$ \\
\hline Acid value in oil & \multicolumn{2}{|c|}{ Always lower } & \multicolumn{2}{|c|}{$\begin{array}{l}\text { After a period of rapid increase, it } \\
\text { tends to be gentle. The higher the } \\
\text { temperature, the shorter the time to } \\
\text { begin to increase. }\end{array}$} \\
\hline
\end{tabular}

O1: Mineral oil O2: Vegetable oil P1: Kraft paper P2: Thermally stabilized paper

(1) Comparison of water content in oil with different insulating oils

The water content of oil in the end of aging is rising, and the water content in plant oil is 10 times or even higher in the ordinary insulating oil, which indicates that the type of oil will affect the aging of insulation, and the temperature will accelerate the aging speed.

(2) Comparison of oleic acid content in different insulating oils

The oleic acid value of vegetable oil combination is far greater than that of mineral oil combination, indicating that the type of oil will affect the aging of insulation, and the temperature will accelerate the aging rate.

(3) Analysis of the low content of oleic acid in mineral oil combinations

Hydrolysis of fat in vegetable oil produces large amounts of water while large amounts of water are consumed.

The decomposition of mineral oil mainly produces small acids, which are more easily adsorbed on insulating paper.

(4) Problems arising

When the moisture in oil increases, the degree of polymerization of paper in vegetable oil is higher than that in mineral oil. The explanation is that vegetable oil will absorb water at the initial stage of degradation, resulting in slower aging rate and increased water content.

At the same time, the content of oleic acid in vegetable oil is much higher than that of mineral oil, which is not consistent with the conclusion of "aging production of oleic acid", and the catalysis of acid on hydrolysis is considered at this time. The effect of temperature is affected by more factors and should be further studied.

\subsection{Experiment 3}

\subsubsection{Phenomenon}

The relationship between the right graph and the right graph is obtained by the experiment.

It can be seen from the diagram that the breakdown characteristics of water to the oil paper insulation structure under DC voltage and AC / DC composite voltage are greater. With the increase of water content in the insulation paper, the breakdown voltage of the oil paper insulation structure under different voltage types shows a downward trend, the decrease amplitude of the DC voltage is the largest, and with the decrease of DC component, the decrease is getting smaller and smaller. The breakdown voltage of insulation structure at AC voltage varies little. 


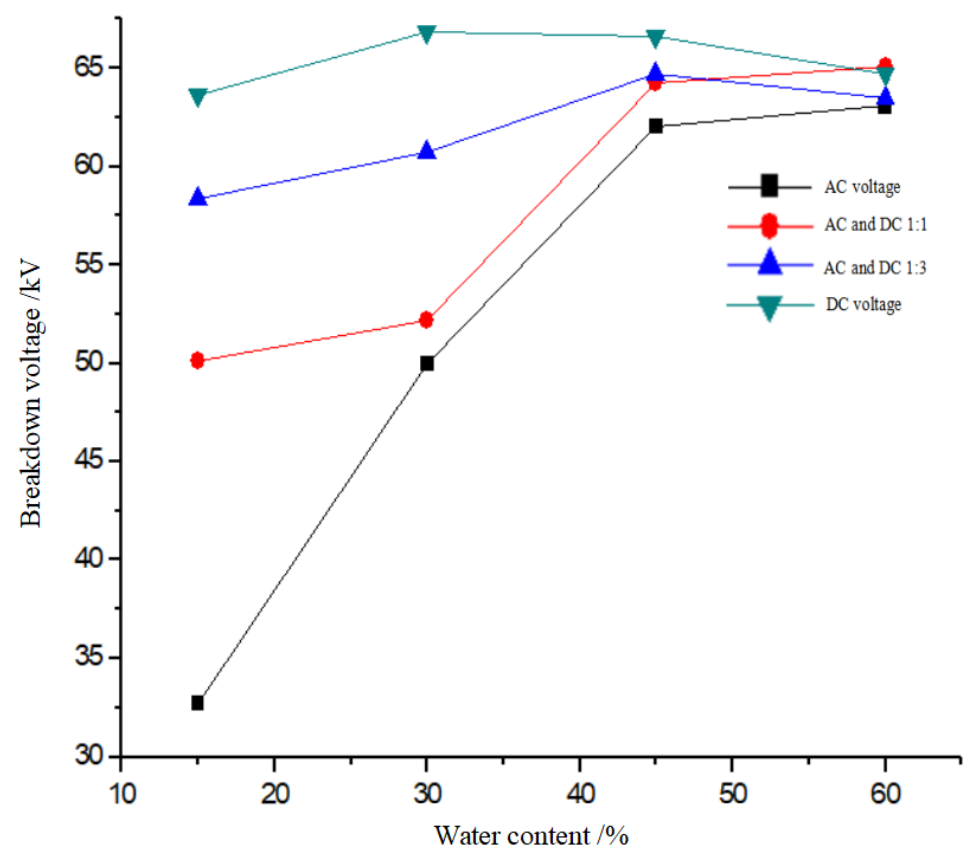

Fig. 2

\subsubsection{Analysis}

Under the action of AC voltage, the electric field distribution inside the oil paper insulation is negatively correlated with the dielectric constant. The dielectric constant e of the dielectric constant of the insulating paper is 1, and the electric field intensity on the insulating paper is E1 on the insulating oil of E2<. Under DC voltage, the electric field distribution in oil paper insulation is positively correlated with volume electrical conductivity. Due to the gamma $2>>$ gamma 1 , the electric field intensity acting on the insulating paper is E2>, the electric field intensity on the insulating oil is E1. Because the electrical strength of the oil immersed insulating paper is "insulating oil", the breakdown voltage of the oil paper insulation system under the DC voltage and the compound voltage $>$ the breakdown voltage under the AC voltage.

For oil paper insulation composites, when the moisture content increases, most of the moisture exists in the insulation paper, while the moisture content in the insulating oil is low. The conductivity of insulating paper and insulating oil will be affected by moisture, because most of the moisture is concentrated in insulating paper, with the increase of moisture content. The electrical conductivity of insulation paper is larger than that of insulating oil, and the distribution of electric field is changed due to the constant electric field distance. At this point, the electric field intensity E2 of the insulation paper decreases, and the electric field intensity E1 of the insulation oil increases, making the insulating oil more easily to breakdown. Therefore, with the increase of moisture content in the oil paper insulation material, the breakdown voltage of the oil paper insulation decreased greatly under the action of compound voltage.

\section{Summary}

The higher the temperature, the faster the aging of oil paper insulation, and the faster the polymerization degree drops. The relationship between aging rate change and temperature stress change is not linear. The more moisture content of oil paper insulation, the faster the aging of oil paper insulation, and the faster the polymerization degree drops. The influence of temperature factor on the aging rate of oil paper insulation will increase with the increase of moisture content in the oil paper insulation system. The influence of water factors on the aging rate of oil paper insulation increased with the increase of temperature. That is, temperature and moisture have a synergistic effect on the aging of oil paper insulation. The higher the aging temperature, the higher the moisture 
content of oil paper insulation, and the faster the furfural generation rate. The furfural content in oil increased slowly at the beginning and increased rapidly in the later stage. The distribution of furfural in oil paper will be affected by moisture content, and the increase rate of furfural content in oil is not corresponding to the rate of decrease in polymerization degree.

\section{Acknowledgement}

This work was supported by NNAS project(No.98548888).

\section{References}

[1] Sun Huigang. Effect of moisture on thermal aging and life span of oil paper insulation and characterization of thermal aging degree [D]. Chongqing, School of electrical engineering, Chongqing University, 2011:15-43.

[2] Liao Ruijin et al. Review on thermal aging of oil paper insulation for power transformers [J]. Acta Electrotechnical Sinica, 2012,27 (5): 1-12.

[3] Wang Gang. Study on the influence of moisture content on the breakdown characteristics of transformer oil paper insulation [D]. Harbin; Harbin University of Science and Technology, 2013:21-33.

[4] Wu Heng et al. Effect of moisture on electrical strength and mechanical strength of oil paper insulation for converter transformer [J]. insulation material, 2017,50 (12): 1-6.

[5] Yang Lijun. Study on aging characteristics and life evaluation method of transformer oil paper insulation [D]. Chongqing; School of electrical engineering, Chongqing University, 2009:34-67.

[6] Liao Ruijin et al. Study on the content of moisture and acid value in different oils and paper insulation combinations during accelerated aging $[\mathrm{J}]$. proceedings of the Chinese Academy of electrical engineering, 2010,5 (2): 1-7.

[7] Yang Fei leopard. Quantitative assessment of water content and insulation aging degree of transformer oil paper [D]. Sichuan, Southwest Jiao Tong University, 2017:26-57.

[8] Gong Jing. Effect of temperature and moisture on aging characteristics and life evaluation of oil paper insulation of transformer [D]. Chongqing, School of electrical engineering, Chongqing University, 2010:19-48.

[9] Daniel Martin, Tapan K. Saha, Tony Gray, Ken Wyper. Determining Water in Transformer Paper Insulation: Effect of Measuring Oil Water Activity at Two Different Locations [J]. IEEE Electrical Insulation Magazine,2015,31(3):1-8.

[10] P. Przybylek. The Influence of Temperature and Aging of Cellulose on Water Distribution in Oil-paper Insulation[D]. Poznan University; Poznan University of Technology Institute of Electric Power Engineering,2013:1-5. 